\title{
查干浑迪花岗岩体的定年和 $\mathrm{Nd}, \mathrm{Sr}, \mathrm{O}$ 同位素研究 ${ }^{*}$
}

周 有 勤

(中国科学技术大学地球和空间科学系,合肥 230026)
王 银 喜

(南京大学现代分析中心，南京 210008)

\section{关键调花岗岩、Rb-Sr 定年、Nd、Sr、O 同位素、岩石成因}

海西中期北疆地区地壳运动强烈, 随着陆壳的开合, 形成了大面积的花岗岩类 ${ }^{[1,2]}$. 在阿 拉套山南坡, 沿博乐铇锡成矿带自东向西分布着孔吾萨依、乌拉斯坦、祖鲁洪、喀孜别克和 查干浑迪等岩体. 其中,西部的祖鲁洪、喀孜别克和查干浑迪花岗岩体与该区的石英脉型、云 英岩型和绿泥石型铇、锡矿化有着直接的关系。本文对查干浑迪花岗岩体进行了 $\mathrm{Sm}-\mathrm{Nd}$, $\mathrm{Rb}-\mathrm{Sr}$ 和 $\mathrm{O}$ 同位素研究, 确定了岩体的形成时代, 探讨了岩体的成因和成岩物质的来源.

\section{1 岩石学特 征}

査干浑迪花岗岩体位于新疆北部博乐铇锡成矿带西段, 温泉县北东约 $16 \mathrm{~km}$ 处. 岩体侵 人于泥盆纪板岩中, 呈岩基产出. 在花岗岩与上覆板岩顶盖的接触带附近形成铇、锡矿化, 矿体 主要赋存在呈雁行排列的 NWW 向花岗岩节理中, 属内接触带花岗岩体内矿化.岩体具有明显 的分带现象. 在岩体的边部及其与残留顶盖的接触带附近, 岩石粒度较细, 常呈细晶花岗岩脉 出现, 构成岩体的边缘相. 在矿体两侧, 由于成矿热液与岩体之间的相互作用, 形成了厚度不等 的云英岩边. 从接触带向内, 岩性比较均一,构成中-粗粒的二云母花岗岩基. 岩石主琶由石 英、钾长石、斜长石、黑云母和白云母组成, 其中石英占 $36 \%$, 钾长石占 $29 \%$, 斜长石占 $25 \%$, 黑云母和白云母约占 $10 \%$. 副矿物有钛铁矿、铅石、磷灰石等. 岩石化学特征是: 酸度高, $\mathrm{SiO}_{2}$ 含量平均 $75 \%$; 碱质含量高, $\mathrm{K}_{2} \mathrm{O}+\mathrm{Na}_{2} \mathrm{O}$ 平均 $7.85 \%$; 铝过饱和, $\mathrm{Al} / \mathrm{NKC}$ 为 1.15 . 岩体具有铇锡成矿母岩的基本特征. 在花岗岩的 QAP 三角分类图上, 查干浑迪岩体寓于二长花岗岩.

\section{2 方法与结果}

根据对岩体的岩石学、矿物学、微量元素和稀土元素研究结果 ${ }^{1)}$, 本文选取 6 个花岗岩全岩 样品和 3 个单矿物样品进行了 $\mathrm{Rb}-\mathrm{Sr}$ 同位素分析, 同时对其中部分全岩样品进行了 $\mathrm{Sm}-\mathrm{Nd}$ 和 $\mathrm{O}$ 同位素分析. 样品中 $\mathrm{Rb}, \mathrm{Sr}, \mathrm{Sm}, \mathrm{Nd}$ 的化学处理及同位素分析均在南京大学现代分析中 心完成, 测定仪器为 VG354 同位素质谱仪. 实验测定 NBS $987 \mathrm{Sr}$ 标样的 ${ }^{87} \mathrm{Sr} /{ }^{86} \mathrm{Sr}=0.71022 \pm$

$1992-06-24$ 收稿, 1992-10-21 收修改稿.

- 中国科学技术大学青年科学基金资助项目.

1) 王㘴仁、周有勤, 新疆博乐铇锡成矿带综合研究报告, 1990,253-274. 
$4(2 \sigma)$, 标准化值采用 ${ }^{86} \mathrm{Sr} /{ }^{88} \mathrm{Sr}=0.1194 ; B C R-1$ 岩石标样中 ${ }^{143} \mathrm{Nd} /{ }^{144} \mathrm{Nd}=0.512662 \pm 8(2 \sigma)$, 标准化值采用 ${ }^{146} \mathrm{Nd} /{ }^{144} \mathrm{Nd}=0.7219$. $\mathrm{Nd}$ 和 $\mathrm{Sr}$ 的全流程 本底分别为 $(5-7) \times 10^{-11} \mathrm{~g}$ 和 $(1-2) \times 10^{-9} \mathrm{~g}$. 详细的分析和测试方法可见文献 [3]. 计算 $\varepsilon_{\mathrm{N}_{d}}(t)$ 和 $\varepsilon_{S_{\mathrm{r}}}(t)$ 时采用 $\left({ }^{143} \mathrm{Nd} /{ }^{144} \mathrm{Nd}\right)_{\mathrm{CHUR}}=0.512638,\left({ }^{147} \mathrm{Sm} /{ }^{144} \mathrm{Nd}\right)_{\mathrm{CHUR}}=0.1967, \quad\left({ }^{87} \mathrm{Sr} /{ }^{86} \mathrm{Sr}\right)_{\mathrm{UR}}=0.7045,\left({ }^{87} \mathrm{Rb} /\right.$ $\left.{ }^{86} \mathrm{Sr}\right)_{\mathrm{UR}}=0.0827, \lambda_{\mathrm{S}_{\mathrm{m}}}=0.654 \times 10^{-12} \mathrm{a}^{-1}, \lambda_{\mathrm{Rb}}=1.42 \times 10^{-11 \mathrm{a}^{-1}}$. 氧同位素分析在中国科 学院地球化学研究所完成. 全部分析结果分别列于表 1 和表 2 中.

表 1 查干浑迪花岗岩的 $\mathrm{Rb}-\mathrm{Sr}$ 和 $\mathrm{O}$ 同位素分析结果

\begin{tabular}{|c|c|c|c|c|c|c|c|c|c|}
\hline 样品编号 & $\begin{array}{l}\text { 样品 } \\
\text { 名称 }\end{array}$ & $\begin{array}{c}\mathrm{Rb} \\
(\mathrm{ppm})\end{array}$ & $\begin{array}{c}\mathrm{Sr} \\
(\mathrm{ppm})\end{array}$ & $\frac{R b}{S r}$ & $\frac{{ }^{87} \mathrm{Rb}}{{ }^{86} \mathrm{~S} r}$ & $\begin{array}{c}{ }^{87} \mathrm{~S}_{\mathrm{r}} /{ }^{806} \mathrm{~S} \mathrm{r} \\
(2 \sigma)\end{array}$ & $\varepsilon_{\mathrm{S}_{r}}(t)$ & $\left({ }^{87} \mathrm{Sr} /{ }^{86} \mathrm{Sr}\right)_{i}$ & $\begin{array}{l}\delta^{18} \mathrm{O} \\
(\% 0)\end{array}$ \\
\hline C- 87030 & 全岩 & 289.8 & 38.69 & 7.49 & 21.72 & $0.799502 \pm 16$ & +81.2 & 0.709874 & +15.22 \\
\hline C- 87023 & 全岩 & 232.6 & 34.91 & 6.66 & 19.32 & $0.788987 \pm 19$ & +72.5 & 0.709263 & +13.37 \\
\hline C-87031 & 全岩 & 275.3 & 45.13 & 6.10 & 17.69 & $0.783552 \pm 20$ & +90.8 & 0.710554 & +11.93 \\
\hline C- 86588 & 全岩 & 297.4 & 62.48 & 4.76 & 4.759 & $0.729943 \pm 15$ & +87.3 & 0.710305 & +10.75 \\
\hline C- 86047 & 全岩 & 306.4 & 60.45 & 5.07 & 14.69 & $0.769865 \pm 25$ & +72.3 & 0.709246 & \\
\hline C-86562 & 全岩 & 291.4 & 49.82 & 5.85 & 16.95 & $0.779691 \pm 9$ & +79.4 & 0.709746 & +13.79 \\
\hline C- 86562 & 长石 & 365.7 & 52.89 & 6.91 & 20.05 & $0.793056 \pm 23$ & +87.5 & 0.710319 & \\
\hline C- 86562 & 黑云母 & 1369.0 & 15.69 & 87.25 & 253.10 & $1.754906 \pm 16$ & +89.9 & 0.710491 & \\
\hline C-86562 & 磷灰石 & 11.18 & 116.70 & 0.096 & 0.0958 & $0.709642 \pm 22$ & +72.3 & 0.709246 & \\
\hline
\end{tabular}

表 2 查干浑迪花岗岩的 $\mathrm{Sm}-\mathrm{Nd}$ 同位索分析结果

\begin{tabular}{c|c|c|c|c|c|c|c|c|c}
\hline 样品编号 & $\begin{array}{c}\text { 样品 } \\
\text { 名称 }\end{array}$ & $\begin{array}{c}\mathrm{Sm} \\
(\mathrm{ppm})\end{array}$ & $\begin{array}{c}\mathrm{Nd} \\
(\mathrm{ppm})\end{array}$ & $\frac{\mathrm{Sm}}{\mathrm{Nd}}$ & $\frac{{ }^{147} \mathrm{~m}}{{ }^{144} \mathrm{Nd}}$ & $\begin{array}{c}{ }^{143} \mathrm{Nd} /{ }^{144} \mathrm{Nd} \\
(2 \sigma)\end{array}$ & $\varepsilon_{\mathrm{Nd}}(0)$ & $\varepsilon_{\mathrm{Nd}}(t)$ & $\begin{array}{c}{ }^{\mathrm{N} d}(\mathrm{M}) \\
(\mathrm{G})\end{array}$ \\
\hline $\mathrm{C}-86562$ & 全岩 & 3.933 & 14.39 & 0.27 & 0.16529 & $0.512516 \pm 20$ & -2.38 & -1.21 & 1.99 \\
$\mathrm{C}-87030$ & 全岩 & 4.356 & 15.28 & 0.29 & 0.17247 & $0.512506 \pm 18$ & -2.58 & -1.67 & 2.38 \\
$\mathrm{C}-86588$ & 全岩 & 4.012 & 13.96 & 0.29 & 0.17387 & $0.512498+16$ & -2.74 & -1.88 & 2.49 \\
\hline
\end{tabular}

\section{3 讨论和结论}

\section{1 花岗岩体的形成时代}

图 1 和图 2 分别给出了查干浑迪花岗岩的全岩 $\mathrm{Rb}-\mathrm{Sr}$ 等时线和全岩-矿物 $\mathrm{Rb}-\mathrm{Sr}$ 内部等 时线年龄图. 根据 York 回归法 ${ }^{[4]}$ 求得全岩等时线年龄为 $288 \pm 2 \mathrm{Ma}$, 全岩一矿物等时线年龄 为 $290.2 \pm 0.1 \mathrm{Ma}$, 二者在误差范围内完全一致. 因此, 这两个年龄数据是可信的, 它们代表 了岩体的形成时代. 从已有资料来看, 査干浑迪岩体的成岩年龄与该区祖鲁洪黑云母二长花 岗岩的全岩 $\mathrm{Rb}-\mathrm{Sr}$ 年龄 $(284.14 \pm 14 \mathrm{Ma})^{[\mathrm{g}]}$ 和喀孜别克二长花岗岩的黑云母 $\mathrm{K}-\mathrm{Ar}$ 年龄 $(298.53 \pm 6.76 \mathrm{Ma})^{1)}$ 接近，与邻区阿尔泰海西期中粒黑云母花岗岩的 $\mathrm{Rb}-\mathrm{Sr}$ 全岩等时年龄 $(291.5 \mathrm{Ma})^{[1]}$ 和中天山北缘华力西中期黑云母花岗岩的全岩 $\mathrm{Rb}-\mathrm{Sr}$ 年龄 $(292 \pm 15 \mathrm{Ma})^{[2]}$ 也 基本一致,反映它们基本上是同时形成的,都是北疆地区海西中期岩浆活动的产物. 同时也表 明,在新疆北部,铇、锡的成矿期主要是海西期. 这与我国南岭地区铇矿化花岗岩主要形成于 燕山期明显不同。

1）周泰䄚等, 博乐铇锡成矿带综合研究报告，1990,92. 


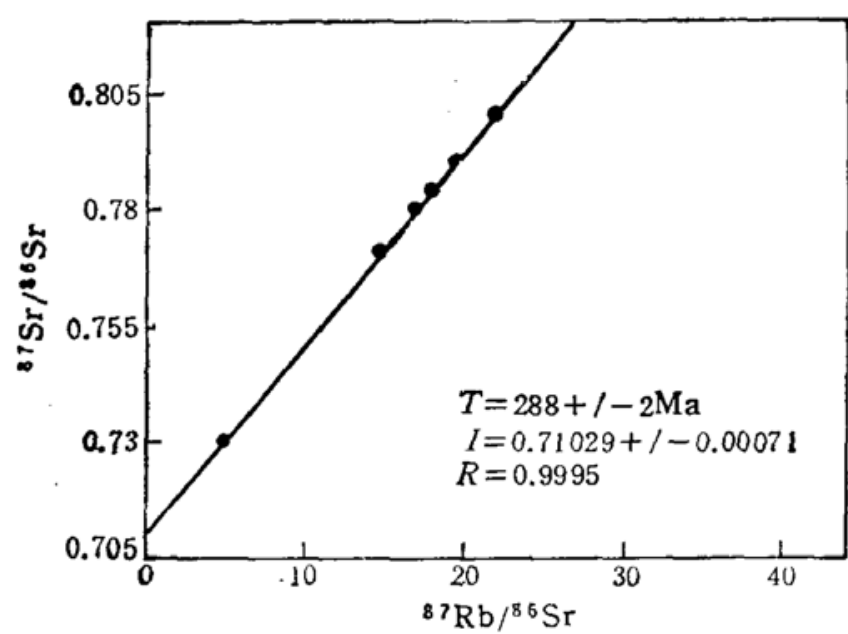

图 1 查干浑迪花岗岩全岩 $\mathrm{Rb}-\mathrm{Sr}$ 等时线

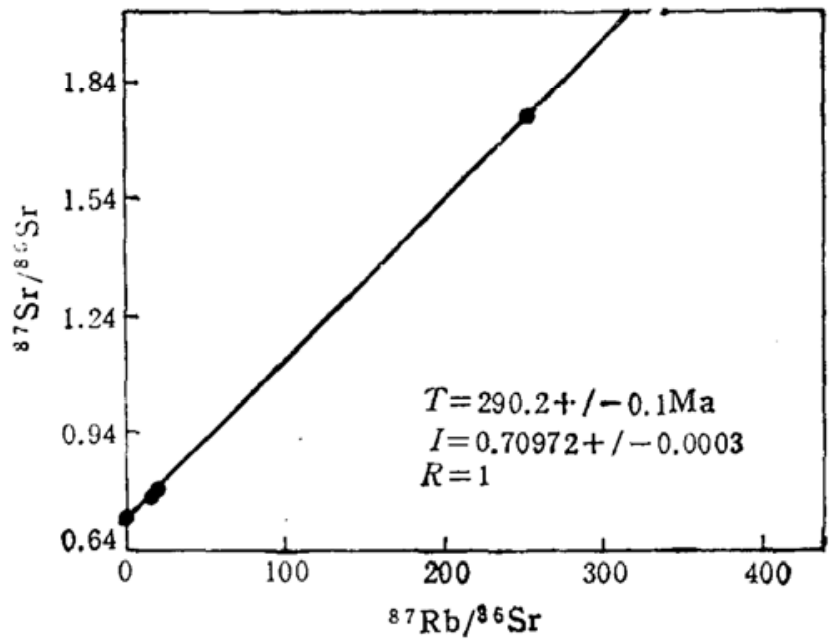

图 2 查干浑迪花岗岩全岩-矿物内部等时线

\section{$3.2 \mathrm{Sr}, \mathrm{Nd}, \mathrm{O}$ 同位素组成特征}

查干浑迪花岗岩的 $\left({ }^{87} \mathrm{Sr} /{ }^{86} \mathrm{Sr}\right)_{i}$ 为 0.7103 , 介于该区壳幔混合成因的祖鲁洪花岗岩体 $(0.7064)^{51}$ 与改造型的中天山东段平顶山、选矿场后山和天 湖 东等岩体的 $\left({ }^{87} \mathrm{Sr} /{ }^{86} \mathrm{Sr}\right) i$ 值 $(0.713-0.718)^{[6]}$ 之间, 与华南陆壳改造型花岗岩 $\left.{ }^{87} \mathrm{Sr} /{ }^{86} \mathrm{Sr}\right)_{i}$ 的下限值 $(0.710)^{[7}$ 相同. 本次 研究的岩体的 $\varepsilon_{S_{r}}(t)$ 为正值 (平均 +81.4$), \varepsilon_{\mathrm{Nd}}(t)$ 为负值 (平均-1.6). G. 福尔 曾指出: $\left({ }^{87} \mathrm{Sr} /{ }^{86} \mathrm{Sr}\right)_{i}$ 小于 0.7040 的花岗岩来源于上地幔， $\left({ }^{87} \mathrm{Sr} /{ }^{85} \mathrm{Sr}\right)_{i}$ 在 $0.7040-0.7060$ 之间 的花 岗 岩也可能来源于上地幔, 而 $\left.{ }^{87} \mathrm{Sr} /{ }^{86} \mathrm{Sr}\right)_{i}$ 大于 0.7060 的侵人体则可能是由下部地壳岩石熔融形 成的 ${ }^{[8]}$. 岩石的 $\mathrm{Rb} / \mathrm{Sr}$ 和 $\mathrm{Sm} / \mathrm{Nd}$ 比值亦对成岩物质的来源有指示意义. 华南改造型花岗岩 的 $\mathrm{Rb} / \mathrm{sr}$ 比值(平均 5.77 ) 要比同熔型花岗岩 (平均 0.52 ) 高一个数量级 ${ }^{[n]}$. 一般地壳花岗岩 的 $\mathrm{Sm} / \mathrm{Nd}$ 比值为 $0.11-0.24^{[9]}$, 地幔该比值则为 $0.32^{[10]}$. 查干浑迪花岗岩的 $\left({ }^{87} \mathrm{Sr} /{ }^{86} \mathrm{Sr}\right)_{i}$ 为 $0.710, \varepsilon_{\mathrm{Nd}}(t)$ 为 $-1.6, \mathrm{Rb} / \mathrm{Sr}$ 比值为 $5.99, \mathrm{Sm} / \mathrm{Nd}$ 比值为 0.28 . 结合岩体的高 ${ }^{18} \mathrm{O}$ 特征 (表 1), 有理由认为查干浑迪花岗岩的成岩物质主要来源于地壳, 其地壳组分所占比例明显大 于该区同时代的祖鲁洪壳幔混合成因花岗岩. 但是, 如果将查干浑迪花岗岩的 $\mathrm{Nd}, \mathrm{Sr}$ 同位素 组成与中天山、华南和葡萄牙北部的壳型花岗岩及澳大利亚南部的 $S$ 型花岗岩相比, 便不难看 出它们在物源上还是存在一定差异的, 前者含有相对较多的幔源物质. 在中天山东段, 明显 具有壳源特征的平顶山、选矿场后山和天湖东岩体的 $\left({ }^{87} \mathrm{Sr} /{ }^{86} \mathrm{Sr}\right)_{i}$ 为 $0.713-0.718, \varepsilon_{\mathrm{Nd}}(t)$ 为 $-3.8--7.6^{66}$; 华南改造型花岗岩的 $\left({ }^{87} \mathrm{Sr} /{ }^{86} \mathrm{Sr}\right)_{i}$ 为 $0.709-0.741^{17}, \varepsilon_{\mathrm{Nd}}(t)$ 为 $-3.8-$ $-18.2^{\mathrm{t11}}$; 葡萄牙北部阿尔瓦伦加、格鲁和瓦莱多高等海西中期二云母花岗岩的 $\left({ }^{87} \mathrm{Sr} /{ }^{86} \mathrm{Sr}\right)_{i}$ 为 $0.711-0.727, \varepsilon_{\mathrm{Nd}}(t)$ 为 $-5.7-7.5^{1)}$, 与澳大利亚南部的 $S$ 型花岗岩 $\left(\left({ }^{87} \mathrm{Sr} /{ }^{86} \mathrm{Sr}\right)_{i}=\right.$ $\left.0.7094-0.7184, \varepsilon_{\mathrm{N}_{d}}(t)=-6.1--9.8\right)^{[12]}$ 基本相同, 表现出明显的壳源特征. 与上述各类 花岗岩相比, 查干浑迪花岗岩具有相对较低的 $\left({ }^{87} \mathrm{Sr} /{ }^{86} \mathrm{Sr}\right)_{i}$ 值和相对较高的 $\varepsilon_{\mathrm{Nd}}(t)$ 值. 这种 差异可能与源岩中地壳组分的比例不同有关. 由表 2 可见, 查干浑迪岩体的 $\mathrm{Nd}$ 模式年龄为 $1.99-2.49 \mathrm{Ga}$ ，它代表了源区物质从地幔中分出的时间. $t_{\mathrm{DM}}^{\mathrm{Nd}}$ 的差异反映了源岩壳幔分异时 间的不同, 暗示花岗岩的成岩物质可能由地壳年龄不同的源区物质所组成. 已有资料表明, 该 区迄今为止已知的最古老地层之一一下元古界温泉群的同位素年 龄为 $19-22$ 亿年 ${ }^{[3]}$. 因

1）周有勤等,萳荡牙北部阿尔瓦伦加-格鲁花岗岩的形成时代和物质来源，1992. 
此, 从 $\mathrm{Nd}$ 模式年龄来看, 查干浑迪岩体的成岩物质有可能来源于早元古代地壳物质.

综上所述,查干浑迪花岗岩体的形成时代为 $290 \mathrm{Ma}$ 左右, 与该区的祖鲁洪和喀孜别克岩 体一样, 都是海西中期北疆大规模岩浆活动的产物. 岩石具有较高的 $\left({ }^{87} \mathrm{Sr} /{ }^{86} \mathrm{Sr}\right)_{i}$ 负的 $\varepsilon_{\mathrm{Nd}}(t)$ 和高的 $\delta{ }^{18} \mathrm{O}$ 值, 反映该岩体以改造型花岗岩为主要特征, 可能由早元古代地壳物质在海西 期构造运动影响下, 在地壳深部发生部分熔融所形成. 成岩物质主要来自于下地壳, 这种地壳 含有较多的幔源物质.

致谢 本文得到中国科学技术大学王奎仁教授和㡀萄牙科英布拉大学 A. M. R. Neiva 教授的指导与帮助,在此一并致以衰心的谢意.

\section{考文神}

[1] 邹天人等,地质学报, $1988,(3): 228-243$.

[2] 王作勋等, 天山多旋回构造演化及成矿, 科学出版社, 北京, 1990,45--62.

[3] 王银喜等,南京大学学报(自然科学版), 1988,24: 297-308.

[4] York, D., Earth Planet. Sci. Lett., 1969, 5:320-324.

[5] 周有勤、王梩仁、王俊新,科学通报, 1991,36(18): 1407-1409.

[6] 王银喜等,岩石学报, 1991,(3): 19--26.

[7]徐克勤等,花岗岩地质和成矿关系,江苏科学技术出版社, 湳京, 1984,1-20.

[8] G.福尔著(潘曙兰等译), 同位素地质学原理,科学出版社,北京, 1983,102.

[9] Hawkesworth, C. J., Rare Earth Element Geochemistry, Elsevier, 1984, 375-416.

[10] Henderson. P., Rare Earth Element Geochemistry, Elsevier, 1984, 1-20.

[11] 袁忠信、张宗清,地质论评, 1992,38(1): 1-15.

[12] McCulloch, M. T., Chappell, B. W., Earth Planet. Sci. Lett., 1982, 58:51-64.

[13] 吴文查等,全国第四届矿物岩石地球化学学术讨论会论文摘要汇编,地震出版社,北京, 1991,246-247. 